\title{
Layered Boron-Nitrogen-Carbon-Oxygen Materials with Tunable Composition as Lithium-Ion Battery Anodes
}

\author{
Jonathan Tzadikov, ${ }^{[a]}$ Mahmud Auinat, ${ }^{[\mathrm{b}]}$ Jesús Barrio, ${ }^{[\mathrm{a}]}$ Michael Volokh, ${ }^{[\mathrm{a}]}$ Guiming Peng, ${ }^{[\mathrm{a}]}$ \\ Christel Gervais, ${ }^{[\mathrm{cc}}$ Yair Ein-Eli, ${ }^{[\mathrm{b}]}$ and Menny Shalom*[a]
}

\begin{abstract}
The insertion of heteroatoms with different electronegativity into carbon materials can tune their chemical, electronic, and optical properties. However, in traditional solid-state synthesis, it is challenging to control the reactivity of monomers, and therefore, the amount and position of heteroatoms in the final materials. Herein, a simple, scalable, and general molten-state route to synthesize boron-nitrogen-carbon-oxygen (BNCO) materials with tunable boron-nitrogen-carbon composition, as well as electronic and optical properties, is reported. The new synthetic approach consists of polycyclic aromatic hydrocarbons (PAHs) and ammonia-borane as reactants that form a
\end{abstract}

clear liquid-state stage spanning a wide temperature range, before the solid-state reaction. The molten-state stage enhances the control over the synthetic intermediates and final materials, owing to improved monomer miscibility and reactivity. The BNCO composition and optical properties are tuned by the PAH selection and final reaction temperature. The advantages of this method are demonstrated herein through the tunable optical properties, excellent stability to oxidization, facile deposition on substrates, and good activity as an anode material in lithium-ion batteries.

\section{Introduction}

Carbon materials have been the focus of immense research due to their unique conductivity and electronic properties. ${ }^{[1,2]}$ The introduction of heteroatoms with different electronegativity, relative to carbon, such as boron, nitrogen, and oxygen, into a carbon material can significantly alter the optical and electronic properties, as well as sensing and catalytic activity. ${ }^{[3-8]}$ Therefore, boron-carbon-nitrogen-oxygen (BNCO) materials are considered to be very promising materials for various applications, such as electronic, optical, and electrochemical devices, owing to their tunable optical and electronic properties, which depend only on the amount and spatial organization of heteroatoms. Traditional BNCO synthetic methods include solid-state reactions, ${ }^{[9]}$ chemical vapor deposition (CVD) ${ }^{[10]}$ and organic addition reactions of BN to polycyclic aromatic hydrocarbons (PAHs). ${ }^{[11]}$ Although an impressively wide

\footnotetext{
[a] J. Tzadikov, J. Barrio, Dr. M. Volokh, Dr. G. Peng, Prof. M. Shalom Department of Chemistry and

Ilse Katz Institute for Nanoscale Science and Technology

Ben-Gurion University of the Negev

Beer-Sheva 8410501 (Israel)

E-mail:mennysh@bgu.ac.il

[b] Dr. M. Auinat, Prof. Y. Ein-Eli

Department of Materials Science and Engineering

Technion-Israel Institute of Technology Haifa 3200003 (Israel)

[c] Prof. C. Gervais

Sorbonne Université, Collège de France

Laboratoire de Chimie de la Matière Condensée de Paris (LCMCP) UPMC Universite Paris 6, UMR CNRS 7574

4 place Jussieu, 75252 Paris cedex 05 (France)

$\square$ Supporting Information and the ORCID identification number(s) for the

(iD)

author(s) of this article can be found under:

https://doi.org/10.1002/cssc.201801438.
}

range of materials were synthesized by these methods, there are still some drawbacks that limit further progress in this field. The CVD method offers low scalability, whereas the solid-state reaction provides moderate control over the composition and position of heteroatoms within the carbon network and usually includes templating, ${ }^{[12]}$ external media, ${ }^{[13]}$ and condensation of different solid powders. ${ }^{[14]}$ Because the reactive interface of solids is their surface, fine-tuning the elemental composition within a BNCO composite is limited to the surface of the solid reactants. In addition, the reactivity of monomers is impeded by the difficulty of achieving their homogeneous distribution. Unlike solid-state reactions, in a liquid, the miscibility of reactants ensures both the homogeneity and high reactivity of monomers; thus enhancing control over the synthetic intermediates and final products. We envision that a liquid-state stage spanning a wide temperature range, before the solidstate reaction, will circumvent many of the solid-state reaction limitations. This method might pave the way for the synthesis of new BNCO and other materials with desirable electronic and chemical properties and controllable elemental composition.

Herein, we report a new and straightforward approach to synthesize BNCO materials with controllable elemental ratio and tunable optical and electronic properties by using PAHs, ranging from naphthalene (Naph) to fluoranthene (Flu), and ammonia-borane $(A B)$ as starting monomers. Upon calcination at high temperatures, the two monomers form a clear liquid solution up to about $400^{\circ} \mathrm{C}$, before their final condensation into BNCO materials. A detailed structural analysis reveals that the monomers react in the liquid phase and establish boronnitrogen-carbon (BNC) bonds. The final BNC composition and BNCO photophysical properties can be easily altered by the 
starting $\mathrm{PAH}$ and calcination temperature. Furthermore, the liquid state enables the growth of continuous and thick BNCO layers on substrates. The good electronic properties are exemplified by their utilization as an anode material for lithium-ion batteries.

\section{Results and Discussion}

BNCO materials were prepared by mixing $A B$ and pyrene (Pyr) at a molar ratio of $1: 1$. The $\mathrm{BNPyr}_{x}$ ( $x=$ final condensation temperature) materials were synthesized by placing the monomers in a ceramic crucible and heating to varying temperatures under a $\mathrm{N}_{2}$ atmosphere (Scheme 1). Upon heating, the two monomers exhibit a melting point in the range of $100-150^{\circ} \mathrm{C}$. Together, the molten monomers are miscible and, above $150^{\circ} \mathrm{C}$, a milky homogeneous liquid is formed (Figure S1 in the Supporting Information).

XRD patterns (Figure S2a in the Supporting Information) show that below $350^{\circ} \mathrm{C}$ the monomers does not fully react and mainly patterns of the starting reactants are detected. For BNPyr $_{350-700}$, the XRD patterns imply the formation of layered carbon-like materials. The wide peak at around $22.1^{\circ}$ for $\mathrm{BNPyr}_{350}$ corresponds to an interplanar stacking of BN-containing polymeric materials ${ }^{[15]}$ and amorphous graphite. ${ }^{[16]}$ This peak is shifted to higher values, reaching $24.2^{\circ}$ in $\mathrm{BNPyr}_{700}$, which indicates a smaller distance between the layers in the layered structure as the synthetic temperature rises. FTIR spectra (Figure S2 b in the Supporting Information) show a combination of characteristic BNCO composite bonds, which are present in all synthesized materials. The weak band at $\tilde{v}=$ $1406 \mathrm{~cm}^{-1}$ is attributed to the $\mathrm{B}-\mathrm{N}$ stretching mode and the intense band at $\tilde{v}=782 \mathrm{~cm}^{-1}$ is associated with $\mathrm{B}-\mathrm{N}-\mathrm{B}$ bending. ${ }^{[17]}$ The bands at $\tilde{v}=1020$ and $1083 \mathrm{~cm}^{-1}$ are related to $\mathrm{N}-$ $\mathrm{B}-\mathrm{O}$ and $\mathrm{B}-\mathrm{O}-\mathrm{B}$ bonds, respectively, ${ }^{[18]}$ whereas the one at $\tilde{v}=$ $1325 \mathrm{~cm}^{-1}$ corresponds to $\mathrm{B}-\mathrm{O} .{ }^{[19]}$ In addition, the presence of a $\mathrm{C}-\mathrm{N}$ bond is apparent from the band at $\tilde{v}=1235 \mathrm{~cm}^{-1}$. [20] The band at $\tilde{v} \approx 1577 \mathrm{~cm}^{-1}$ indicates $\mathrm{C}=\mathrm{C}$ bonds. ${ }^{[21]}$ It seems that the binding of a $\mathrm{BN}$ unit to carbon occurs mainly through $\mathrm{N}$ or $\mathrm{O}$ atoms.

As the final condensation temperature rises above $350^{\circ} \mathrm{C}$, new BNCO materials form with different morphologies and properties to those of the starting monomers. The Raman spectrum (Figure S2C in the Supporting Information) of BNPyr $_{700}$ shows D and G bands at 1340 and $1600 \mathrm{~cm}^{-1}$, respectively. The $G$ and $D$ bands are attributed to typical graphitic ${ }^{[22]}$ and defects bands, respectively. ${ }^{[23,24]}$

SEM images of $\mathrm{BNPyr}_{x}$ at different calcination temperatures (Figure $1 \mathrm{a}-\mathrm{d}$ and Figures S3 and S4 in the Supporting Information) indicate that the new BNCO materials show a relatively consistent morphology, owing to the homogeneous molten phase as an intermediate. Moreover, the materials are composed of spherical particles, ranging from about 15 to $40 \mathrm{~nm}$, due to the formation of a colloidal suspension at high temperature and the boiling of monomers, which possibly results in escaping bubbles. TEM images (Figure $1 \mathrm{e}-\mathrm{h}$ and Figures S5 and $\mathbf{S} 6$ in the Supporting Information) reveal that at lower temperatures there is a blend of thin spherical BNCO particles and some small sheets. As the condensation temperature increases, the BNCO exhibits a layered structure and the morphology of large sheets $(>1 \mu \mathrm{m})$ is observed. EFTEM images (Figure $1 \mathrm{i}-\mathrm{I}$ ) of $\mathrm{BNPyr}_{700}$ show that all elements are uniformly distributed throughout the BNCO material; this demonstrates that the molten reaction forms a homogeneous material.

X-ray photoelectron spectroscopy (XPS; Figure $2 \mathrm{a}-\mathrm{d}$ and Figure S7 in the Supporting Information), thermogravimetric analysis (TGA; Figure $2 \mathrm{f}$ ), and ${ }^{11} \mathrm{~B},{ }^{13} \mathrm{C}$ CP MAS NMR spectroscopy (Figure 3) measurements at different reaction temperatures were acquired to elucidate the reaction path, intermediates, and chemical states of all elements in the final materials.

The B $1 \mathrm{~s}$ XPS spectra (Figure 2a) of $\mathrm{BNPyr}_{350}$ show three peaks at 190.7, 192.7, and $193.9 \mathrm{eV}$, corresponding to $\mathrm{B}-\mathrm{N}_{,}^{[25]}$ $\mathrm{BN}-\mathrm{C}_{1}^{[14]}$ and borate, ${ }^{[26]}$ respectively. These peaks are present in other BNPyr samples as well (Figure S7 in the Supporting Information). All peaks mentioned are slightly shifted to higher binding energies in $\mathrm{BNPyr}_{700}$ due to the partial oxidation of nitrogen. The $\mathrm{C} 1 \mathrm{~s}$ spectra of all BNPyr (Figure $2 \mathrm{~b}$ and Figure $\mathrm{S} 7$ in the Supporting Information) reveal similar existences of $\mathrm{sp}^{2}$ carbon, $\mathrm{C}-\mathrm{N} / \mathrm{C}-\mathrm{O}$, and $\mathrm{C}=\mathrm{O}$ at binding energies of 284.6$284.9,{ }^{[27]} 286.1-286.4,{ }^{[12]}$ and $287.3-287.8 \mathrm{eV}^{[28]}$ respectively. We could observe only a negligible amount (Figure S7 in the Supporting Information) of $\mathrm{C}-\mathrm{B}$ species in $\mathrm{BNPyr}_{500}$ because this bond formation is less favorable energetically. This strengthens the assumption that boron binding occurs mainly through nitrogen and oxygen atoms.

The N 1 s spectra (Figure 2c and Figure S7 in the Supporting Information) for all BNPyr materials were deconvoluted into three peaks centered at 398.2-398.4, 399.0-399.5, and 400.0$400.2 \mathrm{eV}$, which were associated with $\mathrm{N}-\mathrm{B}_{1}^{[14]} \mathrm{N}-\mathrm{C}_{1}^{[29]}$ and amine groups, ${ }^{[27]}$ respectively. For $\mathrm{BNPyr}_{700}$, the amine peak is positivity shifted to $401.7 \mathrm{eV}$, which indicates the formation of protonated nitrogen groups. ${ }^{[27]}$ A new peak at $404.4 \mathrm{eV}$ corresponds to either shake-up ${ }^{[29]}$ or oxidized nitrogen ${ }^{[30]}$. The presence of the abovementioned oxides is confirmed by $01 \mathrm{~s}$ XPS measurements (Figure $2 \mathrm{~d}$ and Figure $\mathrm{S} 7$ in the Supporting Information). Postsynthetic oxidation of BCN materials, owing to their low crystallinity, is well described in literature. ${ }^{[31]}$ EELS results for BNPyr $_{700}$ (Figure 2e) reveal typical B (188 eV), N $(400 \mathrm{eV}), \mathrm{C}(284 \mathrm{eV})$, and $\mathrm{O}(530 \mathrm{eV}) \mathrm{K}$ edges. All atoms show a doublet of $\pi^{*}$ and $\sigma^{*}$, which indicates a covalently bonded $\mathrm{sp}^{2}$ hybridized system of BNCO. ${ }^{[6]}$

The growth mechanism and reaction steps of the BNCO materials were studied by TGA of $A B$ mixed with Pyr (Figure $2 \mathrm{f}$ ) under $\mathrm{N}_{2}$. The reaction can be divided into three main stages. First, from 25 to $147{ }^{\circ} \mathrm{C}$, there is a small weight loss, which corresponds to hydrogen release from the $A B$ monomer and moisture evaporation. ${ }^{[33]}$ The second weight loss, from 148 to $204^{\circ} \mathrm{C}$, the point at which both monomers melt and form a 
stable solution, can be attributed to the release of gaseous molecular aminoborane. ${ }^{[33]}$ The most prominent weight loss (69\%) occurs between 205 and $401^{\circ} \mathrm{C}$, with a maximum at $320^{\circ} \mathrm{C}$, at which the monomers react with one other. During condensation, borazine and hydrogen are released, ${ }^{[33]}$ and some unreacted monomers are evaporated.

This reaction temperature is typical for the condensation of carbon materials. The reaction can be easily scaled up, as exemplified here by a single synthesis of $2 \mathrm{~g}$ of BNCO material (Figure S8 in the Supporting Information). It is important to note that the pyrolysis of Pyr solely results in its full evaporation and decomposition, and no materials were observed afterwards (Figure S9 in the Supporting Information). AB condenses into white $\mathrm{BN}$-like materials at high temperature, as previously reported (Figure S10 in the Supporting Information). ${ }^{[33]}$ This further accentuates the advantage of the liquid phase, which encourages interactions between the two monomers.

The atomic composition of the materials was thoroughly studied by combining elemental analysis (EA) and inductively coupled plasma (ICP) measurements (Table S1 in the Supporting Information). These measurements clearly affirm the successful synthesis of BNCO materials and a successful incorporation of large amounts of boron, nitrogen, carbon, and oxygen. The amount of carbon changes from $78.8 \mathrm{wt} \%$ for $\mathrm{BNPyr}_{300}$ to $48.9 \mathrm{wt} \%$ for $\mathrm{BNPyr}_{700}$. Upon condensation at $500{ }^{\circ} \mathrm{C}$, the amount of boron rises, reaching $29.9 \mathrm{wt} \%$. Once the condensation temperature reaches $700^{\circ} \mathrm{C}$, the amount of boron stabilizes at around $10 \mathrm{wt} \%$. The starting amount of oxygen is $1.5 \mathrm{wt} \%$, whereas for $\mathrm{BNPyr}_{700}$ it reaches as high as $24.0 \mathrm{wt} \%$. The amounts of nitrogen are slightly lower than that of boron, due to the release of $\mathrm{NH}_{3}$ during the reaction. In addition, the $E A$ and ICP data suggest that the empirical chemical formula is $B_{1.1} N_{1} C_{4.4} \mathrm{O}_{1.7}$, which indicates that three $A B$ units react per Pyr molecule.

Further structural elucidation is provided by solid-state NMR spectroscopy data at different calcination temperatures; this type of spectroscopy is well suited to the structural characterization of BNCO materials. ${ }^{[1]}$ In close agreement with XPS analysis, "B MAS NMR spectra show three main signals at all condensation temperatures: a signal at $\delta_{\text {iso }}=17.6 \mathrm{ppm} \quad\left(C_{\mathrm{Q}}=\right.$ $2.49 \mathrm{MHz}, \quad \eta=0.2)$, corresponding to trigonal $\mathrm{sp}^{2}-\mathrm{BO}_{3}{ }^{\left[{ }^{[34]}\right.}$ a signal at $\delta_{\text {iso }}=0.2 \mathrm{ppm}$ (no quadrupolar shape) due to tetragonal $\mathrm{BO}_{4}{ }^{\left[{ }^{[35]}\right.}$ and a signal at $\delta_{\text {iso }}=28.2 \mathrm{ppm}\left(C_{\mathrm{Q}}=3.0 \mathrm{MHz}, \eta=\right.$ 0.2 ), indicating the presence of planar $\mathrm{BN}_{3}{ }^{\left[{ }^{[36]}\right.}$ which suggests domains of six-membered $\mathrm{BN}$ rings. $\mathrm{BNH}_{2}$ environments ${ }^{[37]}$ ( $\delta_{\text {iso }}=31.1 \mathrm{ppm}, C_{\mathrm{Q}}=3.0 \mathrm{MHz}, \eta=0.2$ ) are also present in $\mathrm{BNPyr}_{300}$, but disappear at higher calcination temperatures following the release of hydrogen and some amine groups. ${ }^{13} \mathrm{C}$ CP MAS NMR spectroscopy measurements of the materials at different temperatures reveal that the chemical environment of the graphitic layer is similar to that of Pyr units (Figure $3 \mathrm{~b}$ ). At $700{ }^{\circ} \mathrm{C}$, the ${ }^{13} \mathrm{C}$ NMR signal centered at $\delta=125 \mathrm{ppm}$ is characteristic of turbostratic graphite, possibly oxidized.

Having all data at hand, we propose the growth mechanism illustrated in Scheme 1 and Scheme S1 in the Supporting Information. Upon heating, the two monomers create a homogeneous and stable liquid solution. Contrary to the traditional solid- state reaction, the liquid phase allows the facile organicchemistry-like reaction of the two monomers up to $400^{\circ} \mathrm{C}$. Our results indicate that the formation of BNCO materials occurs through the formation of carbon-nitrogen and carbon-oxygen bonds, which means that the $A B$ monomer attacks Pyr. At higher temperatures, full condensation to a graphitic carbon with BNO domains is achieved. The similarity of the carbon XPS and ${ }^{13} \mathrm{C}$ NMR spectra of untreated Pyr and the BNCO materials after calcination at elevated temperatures suggests that the products are composed of many Pyr-like units.

The insertion of BN species into the carbon network leads to materials ranging from semiconductors with tunable absorption (Figure $4 \mathrm{a}$ ) to semimetals. ${ }^{[38]}$ The simple alteration of their optical and electronic properties through this synthetic method opens up a variety of possibilities toward their exploitation in various applications.

The optical properties were easily tuned by increasing the condensation temperature. UV/Vis spectra (Figure 4a) of BNPyr $_{x}$ show a redshift in the absorption up to $\lambda=800 \mathrm{~nm}$ with increasing condensation temperature, due to better carbonization of the materials and improved packing between the layers. The normalized PL spectra upon excitation at $\lambda=$ $365 \mathrm{~nm}$ are given in Figure 4b. In accordance with the absorption spectra, a clear redshift of the emission for the materials synthesized at higher temperature was obtained (Figure $4 \mathrm{~b}$ shows the PL spectra of different powder samples excited at $\lambda=365 \mathrm{~nm}$ ). Interestingly, the PL spectrum of $\mathrm{BNPyr}_{500}$ is broader and covers almost all of the visible region; this may be attributed to a new electronic transition, owing to the formation of more defects sites on the surface of the material with increasing condensation temperature. ${ }^{[39]}$ Notably, relative to BNPyr materials, the emission spectrum of Pyr (Figure $4 \mathrm{~b}$ ) is different and blueshifted. Furthermore, the BNCOs can be exfoliated by sonication in 2-propanol, resulting in a stable colloidal suspension with strong and tailored optical properties (Figure S11 in the Supporting Information). The PL spectra of BNCO dispersions are blueshifted relative to the corresponding powders, owing to successful exfoliation of the layers.

To demonstrate the generality of this method, we utilized $A B$ with four other common PAHs, namely, Naph, Ant, Phe, and Flu, as monomers instead of Pyr. The full characterization of all materials at different calcination temperatures is given in Figures S12 and S13 in the Supporting Information. The other $\mathrm{PAH}$ s melt at relativity similar temperatures and establish a homogeneous solution with $A B$. Similar to Pyr, the new PAHs react with $A B$ to form $B N C O$ materials with different photophysical properties, ranging from semiconductors to metals (Figure $4 \mathrm{e}-\mathrm{f}$ ).

EA data (Figure 4d and Table S2 in the Supporting Information) shows that the carbon content within the material changes according to the starting PAHs; thus, the selection of the PAH allows the possibility to tune the final BNCO photo- 
physical and chemical properties. Furthermore, there is a direct correlation between the starting PAH unit and the final optical properties, for example, the BNCO absorption edge ranges from near-UV with Naph to the visible region with Flu. This trend is confirmed by PL measurements (Figure $4 \mathrm{e}$ ), for which BNNaph $_{350}$ exhibits an emission at $\lambda=420 \mathrm{~nm}$, whereas the emission of BNFlu ${ }_{350}$ is redshifted to $\lambda=530 \mathrm{~nm}$.

Another important advantage of this synthetic route lies in its straightforward growth and deposition on substrates, such as FTO. Usually, strong van der Waals interactions in layered materials (e.g., graphitic carbon nitride, boron nitride) and their low solubility make it almost impossible to deposit them on substrates. The molten-phase stage allows the formation of an intimate contact with the substrate. Upon condensation, followed by cooling to room temperature, a uniform layer with tunable optical properties can be acquired. As a proof of concept, we deposited BNCO materials by using the same synthetic approach and placing FTO glass below the starting powder.

Figure $4 \mathrm{C}$ shows images of BNCO materials on FTO glass that were prepared from BNPyr and BNPhe at 350 and $400^{\circ} \mathrm{C}$. SEM images (Figures S15 and S16 in the Supporting Information) confirm the successful deposition of BNCO on FTO glass without pinholes. The UV/Vis absorption edge (Figure 4c) of the covered FTOs is blueshifted compared with the corresponding powder samples, owing to thinner layer deposition. The thin layer also explains the similarity between the XRD patterns of the covered FTOs (Figure S17 in the Supporting Information) and plain FTO. FTIR spectra (Figure S17 in the Supporting Information) shows bands identical to that of BNCO powder. The facile growth of BNCO materials, together with their intriguing photophysical properties, encourage their utilization in photoelectronic devices, such as solar cells, photoelectrochemical cells, and light-emitting diodes.

The insertion of heteroatoms into a carbon matrix usually increases its stability to thermal oxidation. ${ }^{[5]}$ TGA analysis (Figure $\mathrm{S} 18$ in the Supporting Information) shows that $\mathrm{BNCO}_{700}$ exhibits superior stability to oxidation and about $80 \%$ of the starting materials is preserved upon heating to $1000^{\circ} \mathrm{C}$ in air, which indicates that the materials can be used for applications that require high stability to oxidation.

Boron, due to its slightly lower electronegativity than that of carbon, induces electron-rich carbon, whereas nitrogen insertion causes surface defects that result in more reactive sites, ${ }^{[40]}$ which should be beneficial for lithium-ion intercalation. It has been shown that BCN materials have relatively good capacity values when acting as an anode in a lithium-ion cell setup. ${ }^{[41,42]}$ Therefore, we preformed preliminary studies on the utilization of the synthesized BNCO materials for reversible lithium-ion hosting. For this purpose, charge-discharge characteristics of the materials in a half-cell configuration versus lithium metal were evaluated, and the capacity and cycle stability of the BNCOs were deduced. Five samples were synthesized at $700^{\circ} \mathrm{C}$ with $A B /$ Pyr molar ratios of $5: 1,2: 1,1: 1,1: 2$, and 1:5 to determine the optimal composition. FTIR, XRD, EA, and ICP measurements are shown in Figure S19 and Table S3 in the Supporting Information. Notably, at higher calcination temperatures, the activity of the lithium-ion batteries decreases due to an increased number of defects in the structure (Figures S20-23 and Table S4 in the Supporting Information).

The electronic conductivities of samples with $\mathrm{AB} / \mathrm{Pyr}$ molar ratios of $5: 1,1: 1$, and $1: 5$ are $0.01,0.50$, and $0.65 \mu \mathrm{Scm}^{-1}$, respectively; this shows a good correlation between the starting amount of Pyr and C/N ratio (Table S5 in the Supporting Information). ${ }^{[43]}$ Figure 5 presents the charge-discharge profiles of cycles $1,5,10,50$, and 100 of the 1:1 BNPyr $_{700}$ composite electrode material, which were recorded during polarization at a constant current of $0.1 \mathrm{mAcm}^{-2}$ in a half-cell configuration versus $\mathrm{Li}$ metal (Figure $5 \mathrm{a}$ ), and the cycle life stability analysis of the same cell (Figure $5 \mathrm{~b}$ ). The recorded capacity values are comparable to that of state-of-the-art graphite-based

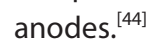

Figure S24 in the Supporting Information presents the life cycle stability of the abovementioned materials with different $\mathrm{AB} /$ Pyr ratios, and it is evident that the ratio between the starting materials has a drastic influence on the measured capacity. Whereas a low Pyr content in the synthesis results in rather low reversible capacity values, the stability of all BNCO materials upon cycling is good. This is strongly evident in Figure $5 c$, which describes the cells being cycled at different current densities, from 0.1 to $1.6 \mathrm{~mA} \mathrm{~cm}^{-2}$ in a reversible staircase mode. Whereas the initial capacity recorded at a current density of $0.1 \mathrm{mAcm}^{-2}$ is $350 \mathrm{mAhg}^{-1}$, it is reduced to slightly to less than $300 \mathrm{mAhg}^{-1}$ if the current density is doubled to $0.2 \mathrm{mAcm}^{-2}$. The materials could sustain high capacity $\left(225 \mathrm{~mA} \mathrm{~h}^{-1}\right)$ if the current was doubled again to $0.4 \mathrm{~mA} \mathrm{~cm}^{-2}$. If the current was drastically increased to 0.8 and $1.6 \mathrm{~mA} \mathrm{~cm}^{-2}$, the capacities were still impressively high: 180 and $140 \mathrm{~mA} \mathrm{hg}^{-1}$, respectively. If the current was decreased back in a staircase mode of operation, the capacities recovered back to their original values. This is a strong indication of rather fast lithium kinetics in the material structure, while maintaining high gravimetric capacities.

The observed capacity trend is expected because the carbonaceous characteristics within the materials might eventually be the factor that determines the reversible capacity. In addition, whereas the measured reversible capacity upon cycling is increased with increased Pyr content, the irreversible capacity, partially associated with the build-up of a passivating film, ${ }^{[45]}$ is quite high for all electrode compositions. This may be well correlated with the relatively high oxygen content in the BNCOs, as discussed earlier. It is postulated that, within the first lithiation processes of the BNCOs, lithium oxide species may be formed. ${ }^{[32]}$ In-depth surface analyses are being planned to better understand the performance of the materials. Such an understanding may pave the way to better design BNCO materials, as well as tuning the electrolyte composition, enabling a substantial decrease in the irreversible capacities, while maintaining the high stability upon extensive cycling.

\section{Conclusions}

We have demonstrated a simple and general molten-state synthesis of BNCO materials with controllable BNC composition and tunable optical, chemical, and electronic properties. The new synthesis becomes possible by using monomers with a distinct molten-phase window at high temperatures, namely, PAHs and AB. Similar to the common organic synthesis approach, the liquid-phase stage endows better miscibility and reactivity of the reactants compared with that of traditional solid-state reactions. Detailed structural analysis of the liquidstate intermediates and final BNCO materials at different calci- 
nation temperatures reveals that the reaction occurs through the establishment of a B-N-C bond, followed by further condensation to BNCO materials. We demonstrated that both the chemical composition and optical and electronic properties could be tuned by selecting different PAHs, owing to the different carbon contents, and calcination temperatures. The liquid-state stage allows the deposition of a thick and uniform BNCO layer on a given substrate. The materials exhibit excellent stability to thermal oxidization, tunability of absorption and photoluminescence properties, as well as good activity as an anode material in lithium-ion batteries. We believe that the generality, simplicity, and scalability of this synthetic approach opens up opportunities for the synthesis of new materials (BNCO and others) with controllable elemental composition, as well as variable optical and electronic properties, toward their utilization in photoelectronic and electrochemical devices.

\section{Experimental Section}

\section{Chemicals}

AB complex (90\%, Sigma-Aldrich, $104^{\circ} \mathrm{C}$ melting point), Naph ( $99 \%$, Acros Organics, $80-82^{\circ} \mathrm{C}$ melting point), Ant ( $99 \%$, Acros Organics, $214-218^{\circ} \mathrm{C}$ melting point), Phe $\left(98 \%\right.$, Alfa Aesar, $97-101^{\circ} \mathrm{C}$ melting point), Pyr ( $98 \%$, Acros Organics, $145-148^{\circ} \mathrm{C}$ melting point), and Flu ( $98 \%$, Sigma-Aldrich, $105-110^{\circ} \mathrm{C}$ melting point) were used as received.

\section{Synthesis}

To prepare BNCO, Naph, Ant, Phe, Pyr, and Flu were mixed with the $A B$ complex at a molar ratio of 1:1. Syntheses were carried out under an inert $\mathrm{N}_{2}$ atmosphere at varying temperatures: 250, 300, $350,400,500,700$, and $800^{\circ} \mathrm{C}$. The mixtures were heated at a rate of $2.4^{\circ} \mathrm{C} \mathrm{min}^{-1}$ and held at the target temperature for $4 \mathrm{~h}$.

To deposit BNCOs on FTO substrates, either Pyr or Phe were mixed with $A B$ complex (1:1 molar ratio) inside a ceramic crucible with FTO-covered glass on its bottom, with the conductive side facing up (facing the powder). Syntheses were carried out to different target temperatures ranging from 350 to $400^{\circ} \mathrm{C}$. The crucibles were heated under a $\mathrm{N}_{2}$ atmosphere at a rate of $2.4^{\circ} \mathrm{Cmin}^{-1}$ and held at the target temperature for $4 \mathrm{~h}$.

\section{Conductivity measurements}

BNCO powders were ground by using a Fritsch Pulverisette 7 planetary ball mill ( $3 \mathrm{~mm} \mathrm{ZrO}_{2}$ balls, for $45 \mathrm{~min}$ ). The powders were then vacuum dried and their $I-V$ curves were measured in a conductivity cell by using a two electrode setup.

\section{Anode electrode preparation}

Preparation of BNCO materials for Li-ion half-cell studies was executed by mixing Pyr with $A B$ at molar ratios of $5: 1,2: 1,1: 1,1: 2$, and 1:5. The mixtures were heated at a rate of $2.4^{\circ} \mathrm{Cmin}^{-1}$ and held at the target temperature for $4 \mathrm{~h}$ under a $\mathrm{N}_{2}$ atmosphere. The obtained materials were ground by using an agate mortar and pestle, followed by 325 mesh sieving, to give particles of less than $44 \mu \mathrm{m}$. Slurries of the active BNCO materials $(90 \mathrm{wt} \%)$ were prepared by mixing them with acetylene black (Super-P carbon), fol- lowed by the introduction of the mixture into $N$-methylpyrrolidinone (NMP) containing dissolved polyvinydene difluoride (PVDF). Electrodes were prepared by doctor blading the slurries on copper foil of $12 \mu \mathrm{m}$ followed by overnight drying in a vacuum oven at $120^{\circ} \mathrm{C}$. The resulting composite BNCO electrodes held $(3 \pm$ $0.2) \mathrm{mg} \mathrm{cm}^{-2}$ with a composition of BNCO/Super-P/PVDF in a ratio of $8: 1: 1$

\section{Electrochemical BNCO anode evaluation}

Disk-shaped electrodes (with a surface area of $1.13 \mathrm{~cm}^{2}$ ) were cut and placed versus lithium-metal disk electrodes in a T-cell shaped electrochemical apparatus, by utilizing ethylene carbonate/dimethyl carbonate (EC/DMC; $1: 3 \mathrm{v} / \mathrm{v}$ ) electrolyte containing $1 \mathrm{M} \mathrm{LiPF}$. These half-cells were studied in a constant-current cycling mode of polarization $\left(0.1 \mathrm{~mA} \mathrm{~cm}^{-2}\right)$ between the potentials of 2.00 and $0.01 \mathrm{~V}$ versus $\mathrm{Li} / \mathrm{Li}^{+}$.

\section{Characterization of materials}

XRD patterns were obtained by using a PANalytical Empyrean diffractometer. A JEOL JSM-7400F high-resolution scanning electron microscope, equipped with a FEG source, operated at $3.5 \mathrm{kV}$. TEM images were recorded on an FEI Tecnai T-12 G2 TWIN instrument operated at $120 \mathrm{kV}$. High-resolution (HR) TEM imaging, EFTEM, and EELS were carried out on a JEOL JEM-2100F analytical transmission electron microscope operated at $200 \mathrm{kV}$ equipped with GATAN 894 US1000 camera. EFTEM experiments were performed by using a Gatan image filter. Carbon $(284 \mathrm{eV})$, oxygen $(532 \mathrm{eV})$, nitrogen $(400 \mathrm{eV})$, and boron $(188 \mathrm{eV}) \mathrm{K}$ edges were used for elemental mapping by means of the three-window method. EELS dispersion: $0.25 \mathrm{eV} / \mathrm{ch}$, aperture $2.5 \mathrm{~nm}$. Scanning TEM (STEM) images were recorded by using a GATAN 806 HAADF STEM detector. The probe size during analysis was set to $1 \mathrm{~nm}$. FTIR spectroscopy performed on a Thermo Scientific Nicolet iN 10MX IR microscope. Optical absorbance spectra were measured by using a Cary 100 spectrophotometer equipped with an integrating sphere, in reflectance mode. Fluorescence measurements were collected by using a FLS920P spectrofluorimeter. The XPS data were collected by using an X-ray photoelectron spectrometer (ESCALAB 250) ultrahigh vacuum (1X $10^{-9}$ bar) apparatus with an $\mathrm{Al}_{\mathrm{K} \alpha} \mathrm{X}$-ray source and a monochromator. The X-ray beam size was $500 \mu \mathrm{m}$ and survey spectra were recorded with a pass energy (PE) of $150 \mathrm{eV}$, and high-energy-resolution spectra were recorded with a PE of $20 \mathrm{eV}$. To correct for charging effects, all spectra were calibrated relative to the $C 1 \mathrm{~s}$ peak, positioned at $284.6 \mathrm{eV}$. The XPS results were processed by using the AVANTAGE software. Solid-state ${ }^{11} B$ MAS and ${ }^{13} \mathrm{C} C P$ MAS spectra were recorded on a Bruker AVANCE 700 spectrometer (16.3 T, $\left.v_{0}\left({ }^{1} \mathrm{H}\right)=700.29 \mathrm{MHz}, \quad v_{0}\left({ }^{11} \mathrm{~B}\right)=224.68 \mathrm{MHz}, v_{0}\left({ }^{13} \mathrm{C}\right)=176.09 \mathrm{MHz}\right)$ by using a $4 \mathrm{~mm}$ Bruker probe and a spinning frequency of $12 \mathrm{kHz}$ for ${ }^{13} \mathrm{C}$ and $14 \mathrm{kHz}$ for ${ }^{11} \mathrm{~B} .{ }^{13} \mathrm{C} \mathrm{CP}$ MAS experiments were recorded with ramped-amplitude cross polarization in the ${ }^{1} \mathrm{H}$ channel to transfer magnetization from ${ }^{1} \mathrm{H}$ to ${ }^{13} \mathrm{C}$. (Recycle delay $=600 \mathrm{~s}$ for Pyr, $3 \mathrm{~s}$ for heat-treated samples, $\mathrm{CP}$ contact time $=1 \mathrm{~ms}$, optimized ${ }^{1} \mathrm{H}$ spinal64 decoupling.) " $B$ MAS NMR spectra were recorded by using a spin-echo $q-t-2 q$ pulse sequence with $q=90^{\circ}$, to overcome problems related to the probe signal. The $t$ delay was synchronized with the spinning frequency. Chemical shift values were referenced to tetramethylsilane for ${ }^{13} \mathrm{C}$ and $\mathrm{BF}_{3} \cdot \mathrm{OEt}_{2}$ for ${ }^{11} \mathrm{~B}$. Mass loss of the monomers, reaction intermediates, and the final material were obtained in a thermogravimetric analyzer (Q500). EA data for CHNSO was collected by using a Thermo Scientific Flash Smart elemental analyzer (OEA 2000). Boron content was acquired by dissolving the 
samples in concentrated nitric acid in an autoclave for $12 \mathrm{~h}$ at $180^{\circ} \mathrm{C}$, and analyzing the sample in a Spectro ARCOS ICP-OES, FHX22 MultiView plasma (SOP, EOP), instrument. The Raman system comprised of a Horiba LabRam HR evolution micro-Raman system, equipped with a Synapse Open Electrode CCD detector air-cooled to $-60^{\circ} \mathrm{C}$. The excitation source was a $\lambda=532 \mathrm{~nm}$ aircooled frequency doubled Nd:Yag laser. The laser power on the sample was about $0.5 \mathrm{~mW}$. The laser was focused with a $\times 100 \mathrm{ob}-$ jective to a spot of about $1 \mu \mathrm{m}$. The measurements were taken with a $600 \mathrm{~g} \mathrm{~mm}^{-1}$ grating and a $100 \mu \mathrm{m}$ confocal microscope hole. The typical exposure time was $30 \mathrm{~s}$.

\section{Acknowledgements}

We thank Dr. Vladimir Ezersky, Dr. Sofiya Kolusheva, Dr. Natalya Froumin, Dr. Leila Zeiri, Dr. Ana Millionshchick, and Dr. Alexander Upcher from the Ilse Katz Institute for Nanoscale Science and Technology for their help in characterizations. We acknowledge financial support from the Israel Science Foundation (ISF, grant no. 1161/17), and the Israel National Research Center for Electrochemical Propulsion (INREP).

\section{Conflict of interest}

The authors declare no conflict of interest.

Keywords: boron-nitrogen-carbon . Li-ion batteries hydrocarbons · electrochemistry · synthesis design

[1] K. S. Novoselov, A. K. Geim, S. V. Morozov, D. Jiang, Y. Zhang, S. V. Dubonos, I. V. Grigorieva, A. A. Firsov, Science 2004, 306, 666-669.

[2] S. Stankovich, D. A. Dikin, G. H. B. Dommett, K. M. Kohlhaas, E. J. Zimney, E. A. Stach, R. D. Piner, S. B. T. Nguyen, R. S. Ruoff, Nature 2006 $442,282-286$

[3] X. Zhao, H. Zhao, T. Zhang, X. Yan, Y. Yuan, H. Zhang, H. Zhao, D. Zhang, G. Zhu, X. Yao, J. Mater. Chem. A 2014, 2, 11666-11671.

[4] Y. Fang, X. Wang, Angew. Chem. Int. Ed. 2017, 56, 2-15; Angew. Chem. 2017, 129, 2-2.

[5] J. P. Paraknowitsch, A. Thomas, Energy Environ. Sci. 2013, 6, 2839.

[6] Z. Chu, Y. Kang, Z. Jiang, G. Li, T. Hu, J. Wang, Z. Zhou, Y. Li, X. Wang, RSC Adv. 2014, 4, 26855-26860.

[7] Y. Lv, S. Chen, Y. Shen, J. Ji, Q. Zhou, S. Liu, Y. Zhang, J. Am. Chem. Soc. 2018, 140, $2801-2804$.

[8] Z. Zhou, Y. Zhang, Y. Shen, S. Liu, Y. Zhang, Chem. Soc. Rev. 2018, 47, 2298-2321.

[9] M. Chhetri, S. Maitra, H. Chakraborty, U. V. Waghmare, C. N. R. Rao, Energy Environ. Sci. 2016, 9, 95-101.

[10] B. Ozturk, A. de-Luna-Bugallo, E. Panaitescu, A. N. Chiaramonti, F. Liu, A. Vargas, X. Jiang, N. Kharche, O. Yavuzcetin, M. Alnaji, M. J. Ford, J. Lok, Y. Zhao, N. King, N. K. Dhar, M. Dubey, S. K. Nayak, S. Sridhar, S. Kar, Sci. Adv. 2015, 1, e1500094.

[11] D. Bonifazi, F. Fasano, M. M. Lorenzo-Garcia, D. Marinelli, H. Oubaha, J. Tasseroul, Chem. Commun. 2015, 51, 15222-15236.

[12] J. Wang, J. Hao, D. Liu, S. Qin, D. Portehault, Y. Li, Y. Chen, W. Lei, ACS Energy Lett. 2017, 2, 306-312.

[13] W. Lei, D. Portehault, R. Dimova, M. Antonietti, J. Am. Chem. Soc. 2011, 133, $7121-7127$.

[14] C. Huang, C. Chen, M. Zhang, L. Lin, X. Ye, S. Lin, M. Antonietti, X. Wang, Nat. Commun. 2015, 6, 7698.

[15] C. Tang, Y. Bando, C. Zhi, D. Golberg, Chem. Commun. 2007, 45994601.

[16] M. Kawaguchi, T. Kawashima, T. Nakajima, Chem. Mater. 1996, 8, 1197 1201.
[17] X. Zhang, Z. Lu, J. Lin, L. Li, Y. Fan, L. Hu, X. Xu, F. Meng, Mater. Lett. 2013, 94, 72-75

[18] X. Zhang, Z. Lu, H. Liu, J. Lin, X. Xu, F. Meng, J. Zhao, C. Tang, J. Mater. Chem. C 2015, 3, 3311-3317.

[19] B. Molina Concha, M. Chatenet, E. A. Ticianelli, F. H. B. Lima, J. Phys. Chem. C 2011, 115, 12439-12447.

[20] B. V. Lotsch, M. Döblinger, J. Sehnert, L. Seyfarth, J. Senker, O. Oeckler, W. Schnick, Chem. Eur. J. 2007, 13, 4969-4980.

[21] L. Zhang, C. Li, A. Liu, G. Shi, J. Mater. Chem. 2012, 22, 8438.

[22] M. J. Allen, V. C. Tung, R. B. Kaner, Chem. Rev. 2010, 110, 132-145.

[23] J. Wang, J. Hao, D. Liu, S. Qin, C. Chen, C. Yang, Y. Liu, T. Yang, Y. Fan, Y. Chen, W. Lei, Nanoscale 2017, 9, 9787-9791.

[24] I. Karbhal, R. R. Devarapalli, J. Debgupta, V. K. Pillai, P. M. Ajayan, M. V. Shelke, Chem. Eur. J. 2016, 22, 7134-7140.

[25] Z. Liu, L. Song, S. Zhao, J. Huang, L. Ma, J. Zhang, J. Lou, P. M. Ajayan, Nano Lett. 2011, 11, $2032-2037$.

[26] H. Konno, H. Oka, K. Shiba, H. Tachikawa, M. Inagaki, Carbon 1999, 37, $887-895$.

[27] J. Barrio, L. Lin, X. Wang, M. Shalom, ACS Sustainable Chem. Eng. 2018, 6, 519-530.

[28] H. J. Shin, K. K. Kim, A. Benayad, S. M. Yoon, H. K. Park, I. S. Jung, M. H. Jin, H. K. Jeong, J. M. Kim, J. Y. Choi, Y. H. Lee, Adv. Funct. Mater. 2009, 19, 1987-1992.

[29] S. C. Yan, Z. S. Li, Z. G. Zou, Langmuir 2010, 26, 3894-3901.

[30] R. J. J. Jansen, H. van Bekkum, Carbon 1995, 33, $1021-1027$.

[31] B. D. Portehault, C. Giordano, C. Gervais, I. Senkovska, M. Antonietti, S. Kaskel, Adv. Funct. Mater. 2010, 20, 1827-1833.

[32] Y. Ein-Eli, V. R. Koch, J. Electrochem. Soc. 1997, 144, 2968.

[33] S. Frueh, R. Kellett, C. Mallery, T. Molter, W. S. Willis, C. King, S. L. Suib, Inorg. Chem. 2011, 50, 783-792.

[34] A. D. Irwin, J. S. Holmgren, J. Jonas, J. Non-Cryst. Solids 1988, 101, 249254.

[35] L. van Wüllen, W. Müller-Warmuth, Solid State Nucl. Magn. Reson. 1993, 2, 279-284.

[36] P. Marchetti, D. Kwon, W. Schmidt, L. Interrante, G. Maciel, Chem. Mater. 1991, 3, 482-486.

[37] V. Lacassagne, P. Florian, V. Montouillout, C. Gervais, F. Babonneau, D. Massiot, Magn. Reson. Chem. 1998, 36, 956-959.

[38] B. T. Ogi, Y. Kaihatsu, F. Iskandar, W. Wang, K. Okuyama, Adv. Mater. 2008, 20, 3235-3238.

[39] X. Zhang, L. Li, Z. Lu, J. Lin, X. Xu, Y. Ma, X. Yang, F. Meng, J. Zhao, C. Tang, J. Am. Ceram. Soc. 2014, 97, 246-250.

[40] J. Wu, M. T. F. Rodrigues, R. Vajtai, P. M. Ajayan, Adv. Mater. 2016, 28, 6239-6246.

[41] M. Ishikawa, T. Nakamura, M. Morita, Y. Matsuda, S. Tsujioka, T. Kawashima, J. Power Sources 1995, 55, 127-130.

[42] Nanotubes and Nanosheets-Functionalization and Applications of Boron Nitride and Other Materials (Ed.: Y. Chen), CRC Press, Boca Raton, FL, 2015, Chap. 3.

[43] G. Dong, K. Zhao, L. Zhang, Chem. Commun. 2012, 48, 6178.

[44] H. Buqa, D. Goers, M. Holzapfel, M. E. Spahr, P. Novák, J. Electrochem. Soc. 2005, 152, A474.

[45] Y. Ein-Eli, Electrochem. Solid-State Lett. 1999, 2, 212.

Manuscript received: June 27, 2018

Revised manuscript received: July 16, 2018

Accepted manuscript online: July 16, 2018

Version of record online: August 19, 2018 


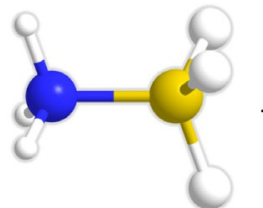

Ammonia - Borane

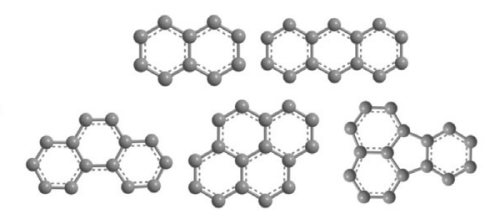

Polycyclic Aromatic Hydrocarbons

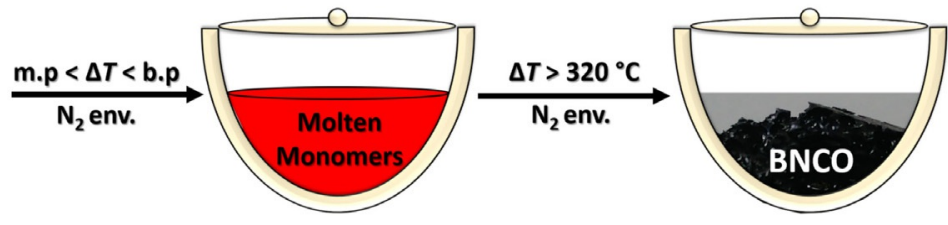

Scheme 1. A general scheme for the synthesis of BNCO.

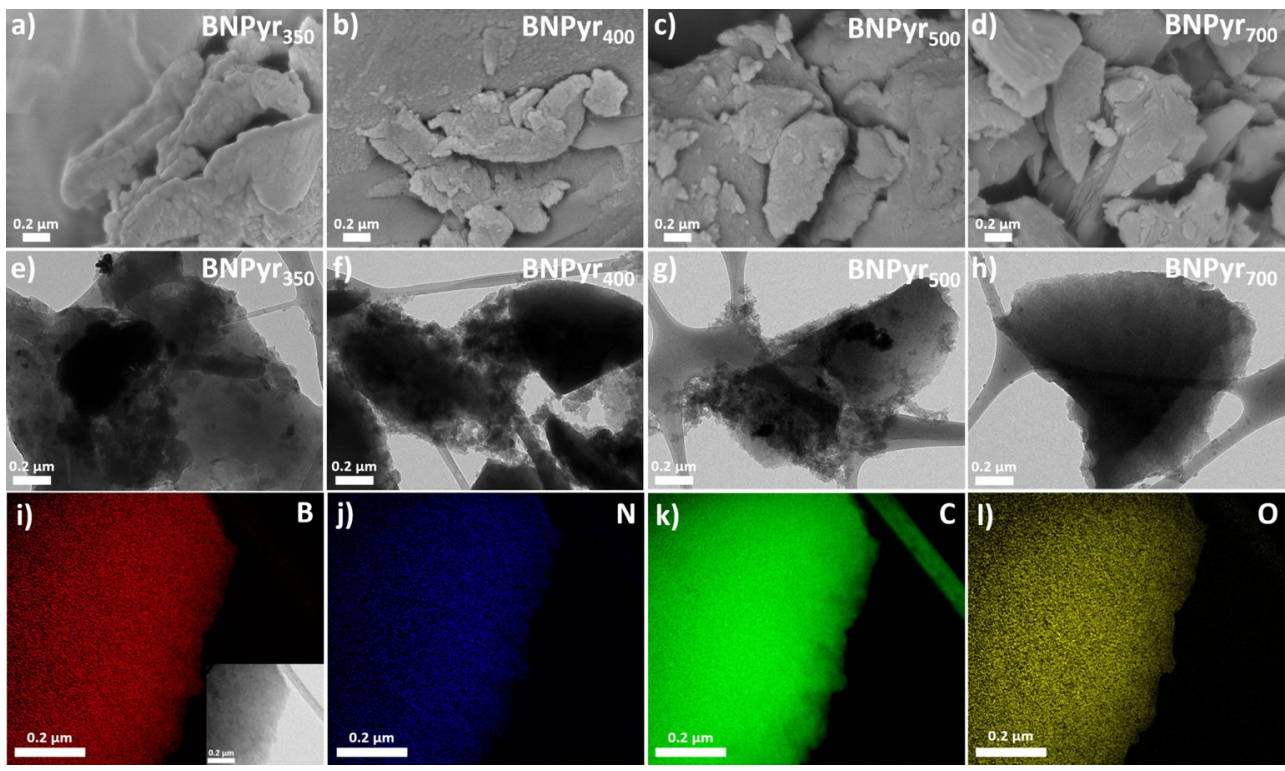

Figure 1. SEM images of BNPyr calcined at a) 350 , b) 400 , c) 500 , and d) $700^{\circ} \mathrm{C}$. TEM images BNPyr calcined at e) 350 , f) 400 , g) 500 , and h) $700{ }^{\circ} \mathrm{C}$. Energy-filtered (EF) TEM images of BNPyr ${ }_{700}$ : i) boron (inset: the corresponding TEM image), j) nitrogen, k) carbon, and I) oxygen. 

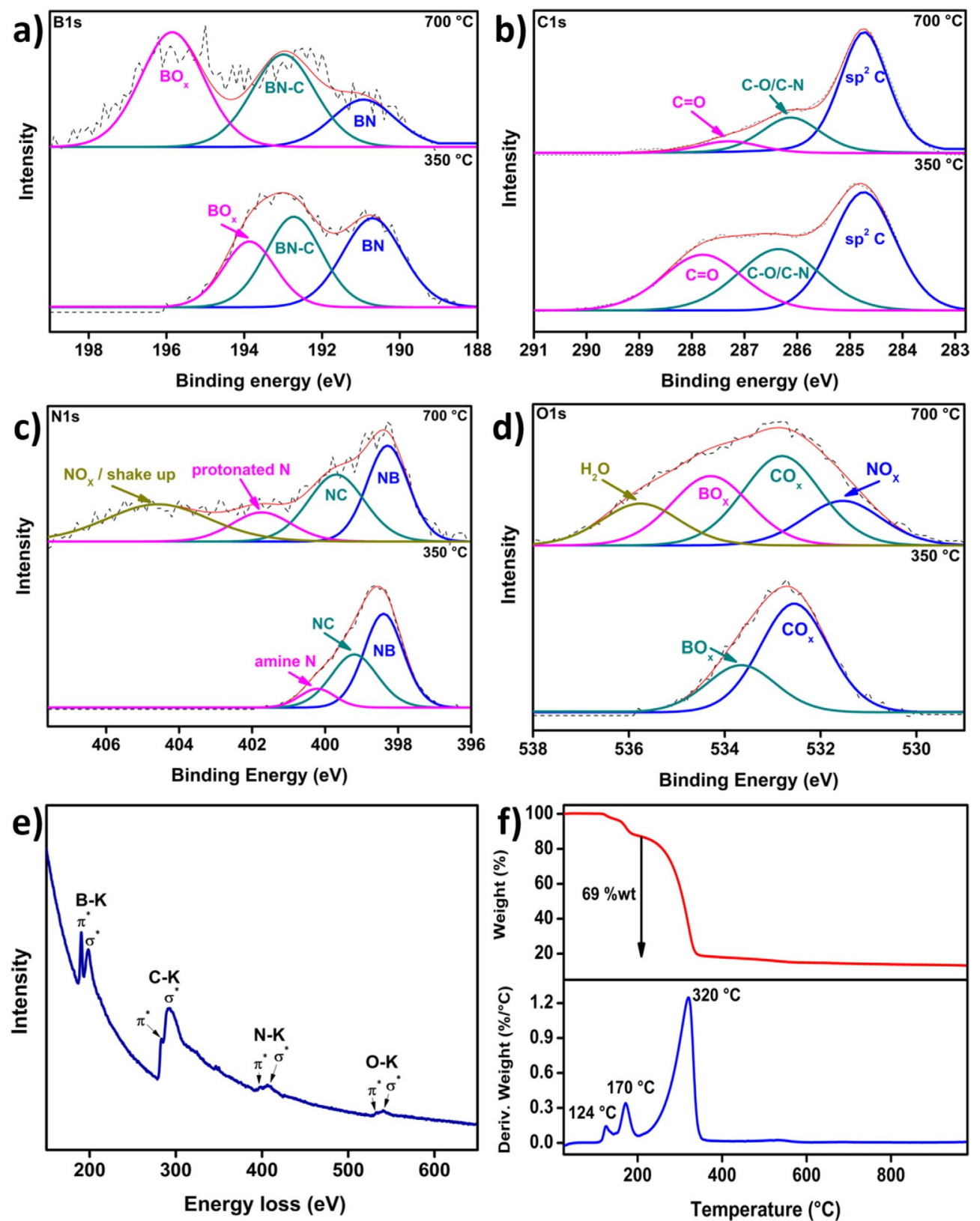

Figure 2. XPS spectra of BNPyr ${ }_{350,700}$ for a) B $1 \mathrm{~s}$, b) C $\left.1 \mathrm{~s}, \mathrm{c}\right) \mathrm{N} 1 \mathrm{~s}$, and d) O $1 \mathrm{~s}$. e) Electron energy loss spectroscopy (EELS) results for BNPyr $\mathrm{r}_{700}$, and f) TGA and derivative weight curves of the reaction between $A B$ and Pyr under $N_{2}$. 

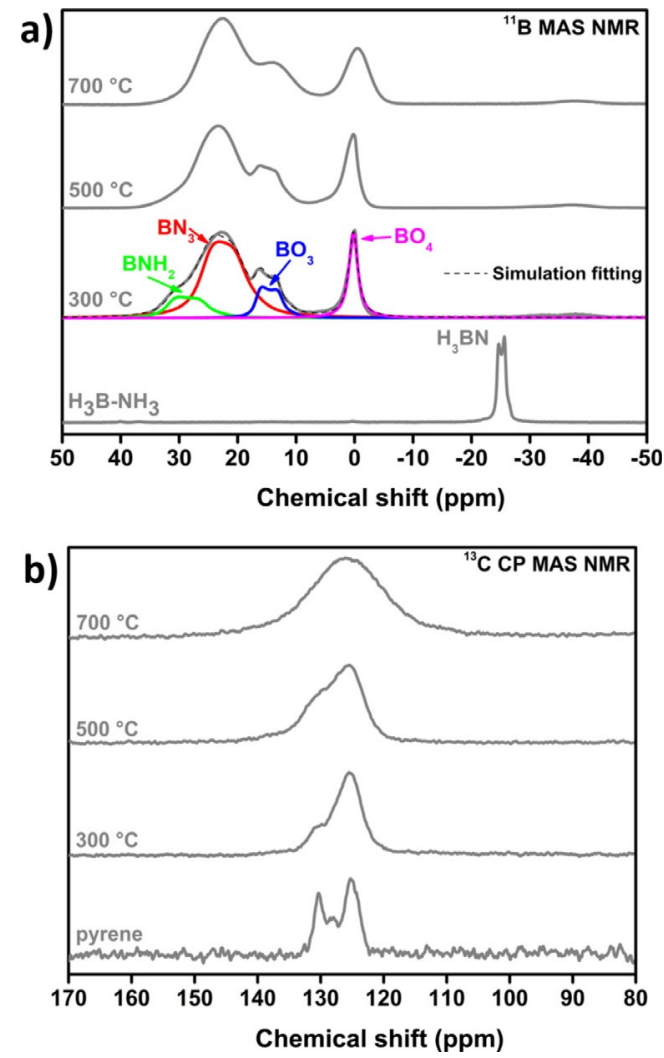

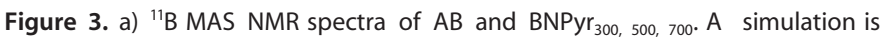
proposed as an illustration for BNPyr ${ }_{300}$; b) ${ }^{13} \mathrm{C}$ CP MAS NMR spectra of Pyr and BNPyr $_{300,500,700 .}$
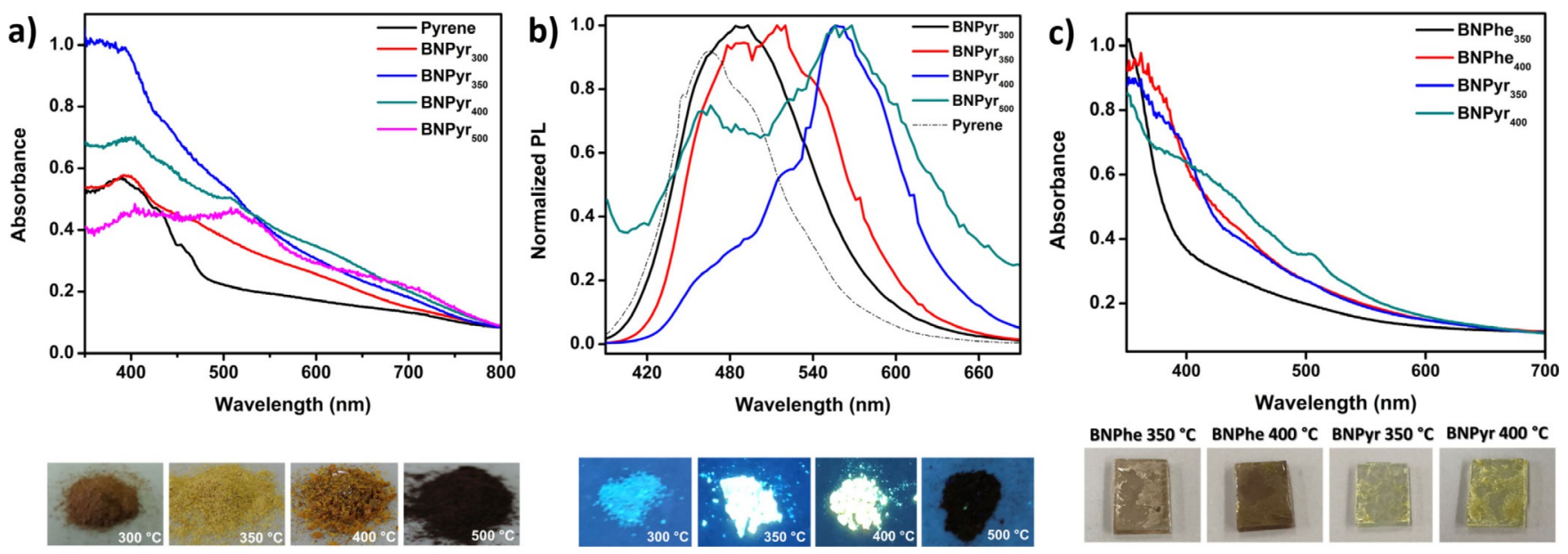

BNPhe $350^{\circ} \mathrm{C}$ BNPhe $400^{\circ} \mathrm{C}$ BNPyr $350^{\circ} \mathrm{C}$ BNPyr $400^{\circ} \mathrm{C}$
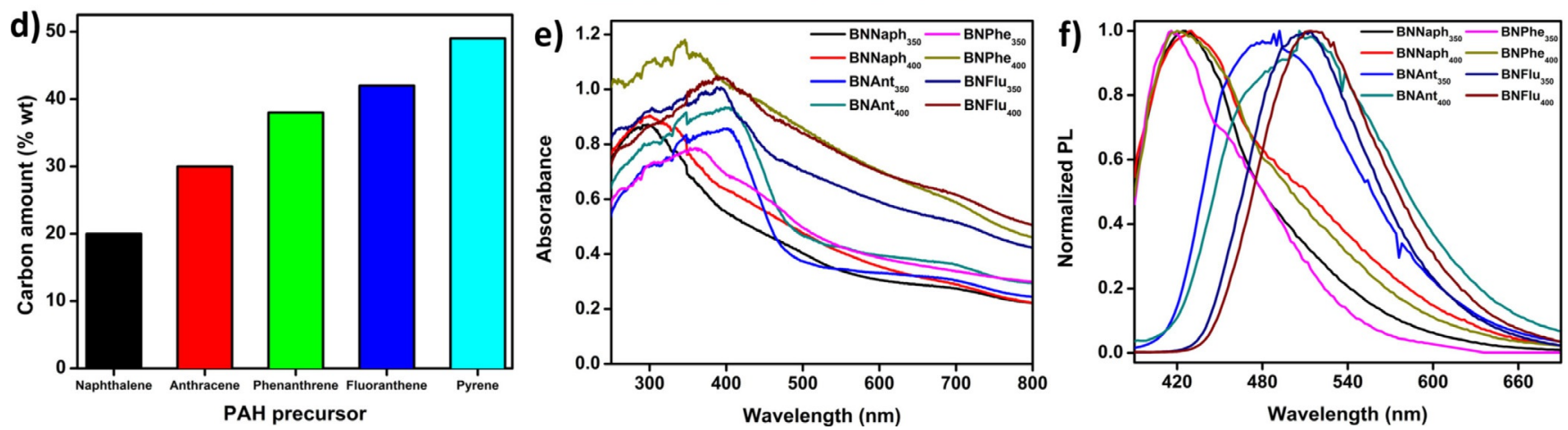

Figure 4. a) UV/Vis and b) normalized photoluminescence (PL; ex. $\lambda=365 \mathrm{~nm}$ ) spectra and images of the powders of BNPyr $\left.{ }_{300,350,400,500 .} \mathrm{c}\right) \mathrm{UV} / \mathrm{Vis}$ spectra of BNPhe $_{350,400}$ and BNPyr $_{350,400}$ on fluorine-doped tin oxide (FTO), and images of the covered FTOs. d) C content in BNCO [wt \%] with different PAHs. e) UV/Vis and f) normalized PL (ex. $\lambda=365 \mathrm{~nm}$ ) spectra of $\mathrm{BNPAH}_{350,400}$ (naphthalene (Naph), anthracene (Ant), phenanthrene (Phe), and fluoranthene (Flu)). The unnormalized PL spectrum is given in Figure S14 in the Supporting Information. 
a)
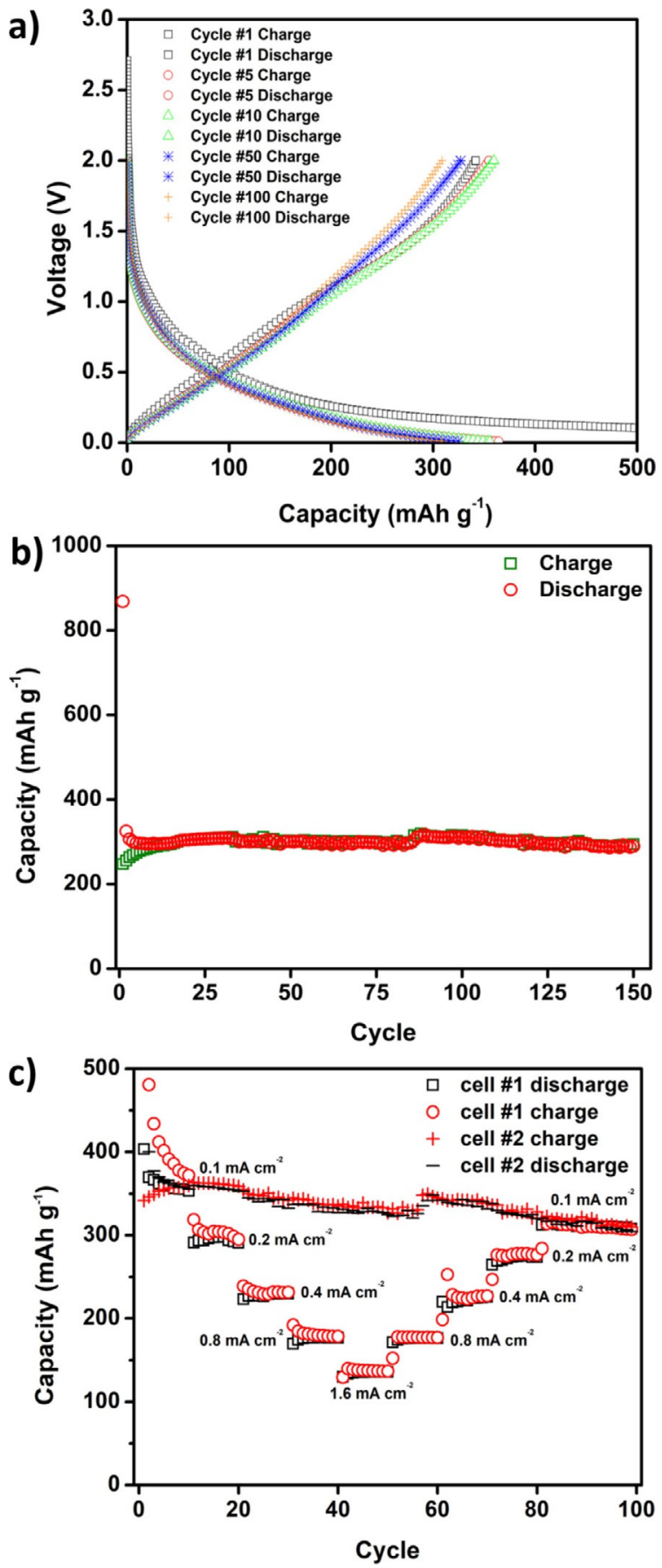

Figure 5. a) Charge-discharge profiles (cycles 1, 5, 10, 50, and 100) of 1:1 BNPyr $_{700}$ obtained from polarization under a constant current of $0.1 \mathrm{~mA} \mathrm{~cm}^{-2}$ in a half-cell configuration versus Li metal. b) Life cycle stability analysis of the same cell. c) Performance rate of BNPyr ${ }_{700}$ material: cells were cycled in a staircase mode of polarization, at different current densities of 0.1$1.6 \mathrm{mAcm}^{-}$. 